\title{
Development and Application of Time-Resolved Surface Plasmon Resonance Spectrometer
}

\author{
Yan Mao, Yu Bao, Wei Wang, Zhenggang Li, Fenghua Li, Li Niu* \\ Changchun Institute of Applied Chemistry, Changchun, China \\ E-mail:lniu@ciac.jl.cn \\ Received March 15, 2011; revised May 3, 2011; accepted May 16, 2011
}

\begin{abstract}
Surface plasmon resonance (SPR) sensor, an optical sensor exploiting special electromagnetic waves-surface plasmon polaritons to probe interactions between an analyte in solution and a molecular recognition element immobilized on the SPR sensor surface, has been widely used in various realms, such as investigating biomolecular interactions and binding properties, detection of biological and chemical analytes, environmental monitoring, food safety and medical diagnostics. This paper reviews the development of SPR sensors and SPR commercial instruments, and emphatically introduces the time-resolved surface plasmon resonance (TR-SPR) techniques. The excellent performances of high sensitivity and rapid detection are easily achieved with TR-SPR spectrometer, whereas the traditional SPR spectrometer cannot be accomplished. Therefore, TR-SPR spectrometer is appropriate for real time analysis of bio-recognition events and small molecular dynamics. However, only two commercial TR-SPR instruments have been exhibited at present, Thermo FT-SPR 100 and Autolab ESPRIT (SPRINGLE). Unfortunately, the high-priced instruments are not suitable for extensive applications in laboratories at present. Herein, a novel commercial TR-SPR spectrometer has been introduced in this review.
\end{abstract}

Keywords: Surface Alasmon Resonance, Time-Resolved Surface Plasmon Resonance, SPR Sensor, Time-Resolved Measurement

\section{Introduction}

Over the past decade, surface plasmon resonance (SPR) sensors have attracted a great deal of attention. Myriads of research reports have appeared describing advancements in SPR sensor technology and its applications. SPR sensor technology has been commercialized and SPR sensors have become a crucial tool for characterizing and quantifying molecular interactions.

SPR detection method can be used to measure the dynamic adsorption process of the biological molecules on the SPR sensor chip surface in real-time and in situ. The concentration of the adsorbed biological molecules can be acquired by measuring the resonance angle offset. In addition, SPR sensor has many advantages, such as can conveniently determine the molecular interactions in real-time, have higher resolution than traditional methods, do not need to tag the sample, require the minimal sample, etc. Therefore, SPR method has become a conventional method on the detection of molecular interactions.
Besides, it has been widely used in the field of life science, such as proteomics [1,2], cell signaling $[3,4]$, receptor/ligand [5-8], antibody/antigen [9-14], immune recognition $[15,16]$, cancer research [17-20] and drug screening [21], etc. SPR method also has been used for real-time dynamic research on protein/protein [22], protein/nucleic acid [23], drug molecule/target protein [24] during the molecular interactions. SPR method is becoming one of the leading analysis technologies for molecular interactions owing to its unique advantages. The sensors based on SPR technology have widely applied in biology, medicine, chemistry and other fields.

Since the performance of SPR sensor is often constrained by certain factors associated with the signalto-noise ratio (SNR) and the response time of the instrument. Sometimes the angular resolution of the instrument can become a limiting factor as well. Hence, improving the resolution and response time of SPR detection are important factors in all SPR sensor applications. Actually, the excellent performances of high sensitivity and rapid 
detection are easily achieved with TR-SPR spectrometer, whereas the traditional SPR spectrometer cannot be accomplished. Thus, TR-SPR spectrometer is suitable for bio-recognition events analysis and small molecular dynamics research. As a consequence, it is necessary to build high-resolution SPR instrument which has several excellent features, include simplicity, good linearity, compactness, and immunity to ambient light. At present, there are several high time-resolved surface plasmon resonance spectrometers in laboratories, which based on a bicell photodetector [25-27] or a large surface area single cell photodiode [28]. However, only two commercial TR-SPR instruments have been exhibited today, Thermo FT-SPR 100 and Autolab ESPRIT (SPRINGLE). Unfortunately, the high-priced instruments are not suitable for wide applications in laboratories. Herein, this paper introduced a novel commercial TR-SPR spectrometer with high angular resolution $\left(0.001^{\circ}\right)$ and time resolution $(<0.1 \mathrm{~ms})$. The time resolution is better than or comparable to those of most published sensograms for commonly studied electrochemical and biological reactions [29-34].

\section{The Principle of SPR Sensor}

The most common approach to excitation of surface plasmons (SP) is by means of a prism coupler and the attenuated total reflection (ATR) method. There are two configurations of the ATR method-Kretschmann geometry [35] and Otto geometry [36].

In the Kretschmann geometry of the ATR method, a high refractive index prism with refractive index $n_{p}$ is interfaced with a metal-dielectric waveguide consisting of a thin metal film with permittivity $\varepsilon_{m}$ and thickness q, and a semi-infinite dielectric film with a refractive index $\mathrm{n}_{\mathrm{d}}\left(\mathrm{n}_{\mathrm{d}}<\mathrm{n}_{\mathrm{p}}\right)$, as shown in Figure 1(a). When a light wave propagating in the prism is made incident on the metal film, a part of the light is reflected back into the prism and the other part propagates in the metal in the form of an inhomogeneous electromagnetic wave [37]. This inhomogeneous wave decays exponentially in the direction perpendicular to the prism-metal interface, so it is referred as to an evanescent wave. If the metal film is sufficiently thin (less than $100 \mathrm{~nm}$ for light in visible and near infrared part of spectrum), the evanescent wave penetrates through the metal film and couples with a surface plasmon at the outer boundary of the metal film.

In the Otto geometry, a high refractive index prism with refractive index $n_{p}$ is interfaced with a dielectric-metal waveguide consisting of a thin dielectric film with refractive index $n_{d}\left(n_{d}<n_{p}\right)$ and thickness $q$, and a semi-infinite metal film with permittivity $\varepsilon_{m}$, as shown in Figure 1(b). A light wave incident on the prism-dielectric film interface at an angle of incidence larger than the critical angle of incidence for these two media produces an evanescent wave propagating along the interface between the prism and the dielectric film. If the thickness of the dielectric layer is proper (typically few microns), the evanescent wave and a surface plasmon at the dielectric-metal interface can couple with each other. For the coupling to occur, the propagation constant of the evanescent wave and that of the surface plasmon have to be matched [38].

Surface plasmon is an electromagnetic wave oscillating on metal surface. Known from the electromagnetic theory, the resonance can take place when two electromagnetic waves with the same frequency and waveverctor. The frequency of surface plasmon triggered by the evanescent wave is the same as the evanescent wave. That is to say, as long as meet the condition, $\mathrm{k}_{\mathrm{x}}=\mathrm{k}_{\mathrm{sp}}\left(\mathrm{k}_{\mathrm{x}}\right.$ and $\mathrm{k}_{\mathrm{sp}}$ corresponds to the wavevector of evanescent wave and surface plasmon which parallel to surface, respectively), the resonance between the evanescent wave and the surface plasmon occurs.

When the resonance occurs, the total internal reflection condition that takes place on the prism and the metal interface is destroyed. It is called the attenuated total internal reflection phenomenon. Thus, the reflection occur a minimum because the energy of the incident light transfer to the surface plasmon. As described above, the generation of the resonance is related to the angle of incident light, the dielectric constant of metal film and the refractive index of medium.

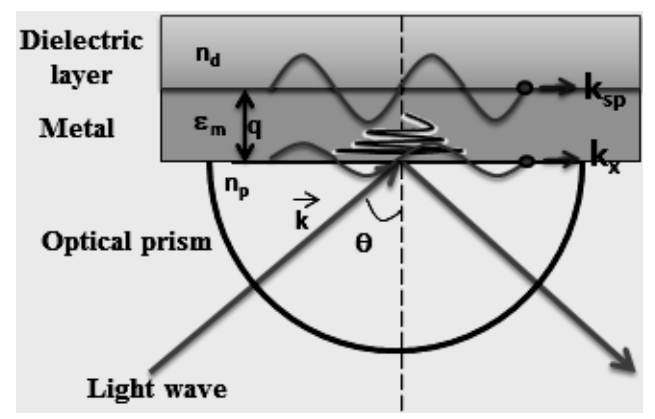

(a)

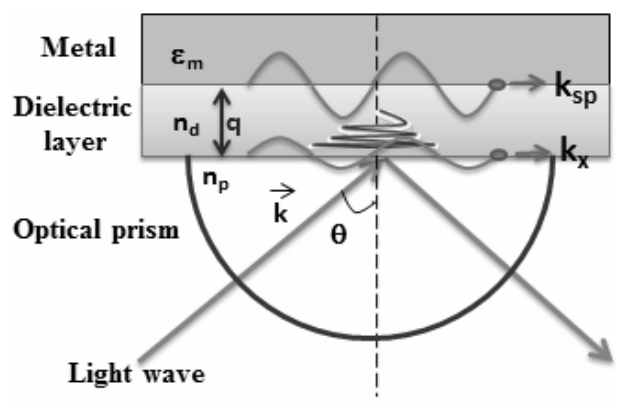

(b)

Figure 1. The schematic diagram of SPR sensor. 
In SPR sensor, a surface plasmon is excited at the interface between a metal film and a dielectric medium (superstrate), changes in the refractive index of which are to be measured. A change in the refractive index of the superstrate leads to a change in the propagation constant of the surface plasmon. This change alters the coupling condition between a light wave and the surface plasmon, which can be observed as a change in one of the characteristics of the optical wave interacting with the surface plasmon [39].

Another approach to optical excitation of surface plasmons in based on the diffraction of light on a diffraction grating [40]. And surface plasmons can be also excited by modes of a dielectric waveguide [41].

\section{The Development of SPR Sensor and SPR Commercial Instruments}

The development of SPR sensor is the pursuit of high resolution and accuracy, and fast response. The optical system of SPR sensor is in a continuous improvement. Based on the method of surface plasmons excitation, there are prism couplers, grating couplers, and waveguide couplers three SPR sensors.

The first documented observation of surface plasmons dated back to 1902, when Wood illuminated a metallic diffraction grating with polychromatic light and noticed narrow dark bands in the spectrum of the diffracted light, which referred as to anomalies $[42,43]$. Theoretical work by Fano [44] concluded that these anomalies were associated with the excitation of electromagnetic surface waves on the surface of the diffraction grating. In 1957, Ritchie explained the phenomenon of energy loss at the interface in theory, and proposed the intrinsic plasmon oscillation model which belonged to metal interface [45]. Two years later, Powell and Swan verified the correctness of the Ritchie's theory experimentally [46]. Stern and Farrell put forward the concept of Surface Plasmon for the first time in 1960 [47]. In 1968, two German scientists, Kretshchmann [35] and Otto [36] used the ATR method to achieve the SPR optical excitation, respectively. And they made the combination of simple optical circuits possible to study the SPR phenomenon (most of the current SPR analysis apparatus still used the similar optical design of them). Otto suggested that under specific condition, the frequency of the incident light and the surface plasmon wave were the same, which would lead to surface plasmon resonance effect. Then he gave the design of the Otto model. Kretschmann proposed a new rough surface perturbation theory, and designed a new Kretschmann model which was the equivalent model of Otto's [48]. The emergence of the two models provided a broad prospect for the SPR sensor in produc- tion and application.

Gordon studied the interface electrochemical properties by SPR method for the first time in 1980 [49,50]. Two Swedish scientists, Nylander and Liedberg, firstly applied SPR technology to chemical sensors field in 1982 [51,52]. Meanwhile, they successfully used SPR technology for gas detection and real-time antigen-antibody interactions monitoring. In addition, they firstly developed the SPR gas sensor and biological sensor triumphantly, which lay the foundation of the biomolecular interactions measurement.

In 1984, Tiefenthaler [53] firstly employed input and output grating couplers and Bragg reflector gratings to demonstrate new switching and gas-sensing effects in integrated optics. In late 1987, Cullen carried out the grating SPR sensor, which acquired information by measuring the changes of light intensity [54]. Vukusic et al. had also realized grating SPR sensor during 19921994, but made use of the wavelength as a variable. The sensor could obtain the measurement sensitivity of 1000 $\mathrm{nm} / \mathrm{RIU}$ (refractive index units) on a silver-coated grating surface [55].

In 1991, Karlsson [56] reported a sophisticated method for analyzing the antigen-antibody immune response dynamics for the first time by employing the BIAcore systems. They calculated the dissociation rate constant of HIV-1 core protein P24 through the mathematical derivation and dynamic analysis. It should be pointed out that this dynamic analysis method can be used for many other affinity reaction categories almost without modification. On the basis of this method, many dynamic analysis methods for other types of biological molecules affinity reactions have been quickly established by the research team of the BIAcore corporation and its cooperation laboratories. Otherwise, in 1992, Fägerstam [57] utilized this system and method for analyzing the growth factor of insulin and the kinetics of binding sites. They successfully carried out dynamic analysis and monitored small molecules in solution, which was another major breakthrough in the detection of biological molecules affinity reactions and kinetic analysis.

The prism couplers SPR senor was not suitable for remote sensing, because the volume of this kind SPR sensor was large. In 1993, Jorgenson and Yee [58] of University of Washington firstly proposed the fiber-optic SPR configuration. They brought forward the fiber core as the carrier of the SPR excitation and employed the fiber as the first layer to substitute the large prism. The sensing element of the fiber has been fabricated by removing a section of the fiber cladding and symmetrically depositing a thin layer of highly reflecting metal onto the fiber core. Furthermore, they suggest such a sensor to 
measure the liquid refractive index with $2.4 \times 10^{-4}-7.5$ $\times 10^{-5}$ accuracy. Meanwhile, due to the small probe of these kind sensors, the object could be detected without destroying the structure, thus further broadening the applications of surface plasma wave sensor.

In 1994, Jory [55] applied the acousto-optic modulator to the grating SPR sensor, which could detect the wavelength change of $5 \times 10^{-4} \mathrm{~nm}$. The resolution of SPR sensor measurement could achieve $1 \times 10^{-6}$ RIU based on this method. In the same year, Nilitin [59] of General Physics Institute of Russian Academy of Sciences, cleverly fabricated SPR grating by using the Schottky-barrier structure in semiconductor technology, and the resolution arrived at $1 \times 10^{-5}$ RIU. While the biggest advantage of this configuration was that the metal layer thickness requirement was less stringent than the coupling prism manner. Since then, some reports on the grating SPR sensor have come forth, but the application scope of these sensors was relatively narrow compared to other types SPR sensors. The main reasons, on one hand, there was a certain degree of difficulty on the grating fabrication. On the other hand, the sample needed to be achromatous in the grating SPR application. For the reason that the light went through the sample during the measurement process, it would produce light absorption if the sample solution was colored which might affect SPR measurements.

Nelson [60] of University of Washington suggested that if the experiment device was well designed, phase detection could measure refractive index change of $5 \times$ $10^{-7}$ RIU after compared the resolution test of the phase detection and the light intensity detection in 1996. In the next year, Nikitin $[61,62]$ reported a novel SPR interferometric technique, and the resolution of SPR interference phase detection was several orders of magnitude higher than the light intensity detection.

In 2002, Ho [63] of the Chinese University of Hong Kong, utilized Mach-Zehnder interferometer to perform interferometric analysis between the two orthogonal polarizations in the exit beam. $\mathrm{Wu}[64,65]$ of Tsinghua University, studied heterodyne interferometric system and further improved the sensor sensitivity and antijamming capability. The refractive index change of $2 \times$ $10^{-7}$ RIU could be detected in the experiment. In 2004 and 2005, Ho et al. [66,67] further improved their proposed approach. They used two interferometric systems to depress the mechanical movement, which could reduce the mechanical error brought from the resulting system. Meanwhile, the noise errors of the system could be eliminated and compensated by taking advantage of digital signal collection and analysis procedure. Therefore, the sensitivity and stability could be improved, and the detection limit was $7.4 \mathrm{ng} / \mathrm{mL}$ experimentally.
The development of SPR sensor is not limited to laboratories. In order to provide effective means for many researchers and promote the greater use of SPR sensors, the commercial SPR instruments developed at a fast speed. The Linkoping Institute of Technology together with the Swedish National Defense Research Institute co-founded the Pharmacia Biosensor AB company (the company changed its name to BIAcore AB in 1996), developed the world's first commercial SPR biomolecular interactions analyzer-BIAcore ${ }^{\mathrm{TM}}$ during 1989 - 1990 [68]. Afterward, the SPR biosensor research has been comprehensively launched and continued to deepen. Meanwhile, the application scope of SPR biosensors was expanding.

A number of commercial SPR sensor instruments are available [69]. Although BIAcore systems have dominated the market since their introduction [70], there are many more competing SPR instruments now available. A list of product names and their manufactures can be found in Table 1.

The BIAcore instruments were the most advanced, sensitive, accurate, reliable, reproducible direct biosensor technique and SPR became (and still is) the "golden standard" of transducer principles for measuring realtime biomolecular interactions. Since the early 1990s, producers have been struggling to meet the standards set by BIAcore. The original BIAcore instruments were fully automated, including sample handing equipment for the immobilization, auto-sampling, SPR analysis, and regeneration of the sensor surface. The instruments permit a range of concentration assay, activity detection, kinetic analysis, affinity measurement, and fast screening.

Table 1. A list of product names and their manufactures.

\begin{tabular}{ccc}
$\begin{array}{c}\text { Product } \\
\text { Name }\end{array}$ & Manufacturer & $\begin{array}{c}\text { Company } \\
\text { Address }\end{array}$ \\
\hline BIAcore & BIAcore AB & Sweden \\
IASys & Affinity Sensors & America \\
Spreeta TM & Texas Instruments & America \\
Quantech SPR & Quantech & America \\
SPR-670 & Nippon Laser \& & Japan \\
Kinomics & Electronics Lab & BioTul Bio \\
IBIS-iSPR & Instruments GmbH & Germany \\
Windsor & IBIS Technologies BV & Netherlands \\
Scientific & Windsor Scientific & United \\
SPR-2000 & Institute of Electronics, & China \\
& Chinese Academy of Sciences & \\
\hline
\end{tabular}


The BIAcore 2000 instrument was introduced in 1994 with improved detection and a different flow system so that the sample could interact at four spots on the sensor. Data of the reference spot could be used for signal correction. With the introduction of BIAcore 2000, it also became possible to monitor directly interactions of small molecule analytes reacting with immobilized protein ligands [71]. Kobayashi [72] used BIAcore 2000 to phase-solubility studies, for evaluating the solubilizing effects of cyclodextrins (CDs) on lipophilic, water-insoluble drugs. Papalia [73] used BIAcore's new regenerateable streptavidin capture (CAP) sensor chips to investigated a number of biotinylation conditions for target ligands by using Biacore 2000 and T100 instruments. Glück [74] employed BIAcore T100 to quantify the binding of the nanodisc-inserted histidine-tagged protein to a monoclonal anti-pentahistidine antibody. Patel [75] used a BIAcore 3000 biosensor to analyze the binding kinetics of a recombinant monoclonal antibodies $(\mathrm{mAb})$ and its single-chain antibody homolog, single-chain variable fragment $(\mathrm{scFv})$.

Fisons Instruments [76] made great attempts to compete with BIAcore's technology. Their cuvette-based IAsys instrument uses evanescent field-based technology, essentially not SPR, for the study of biomolecular interactions. Natori [77] used a surface plasmon resonance (SPR)-based resonant mirror biosensor (IAsys) to analyze the surface properties of phytochrome A (phy A), the epitopes of 21 anti-phy $\mathrm{A}$ monoclonal antibodies were determined by variously engineered recombinant phy A proteins and the dissociation constants of seven anti-phy A monoclonal antibodies with phy A were measured.

The high cost of BIAcore instruments has provided a niche for other companies such as Texas Instruments (TI) to supply inexpensive SPR sensors with immunoassay capability. TI has introduced the SPR device Spreeta [78]. Noteworthy features of the Spreeta device include two thermistors (in the sensor and flow cell) to compensate for SPR's sensitivity to temperature fluctuations. The sensor performance is quantified by a measurable refractive index change of $10^{-5}$ [79]. Nanduri [80] used the Nomadics SPR3 system of a SPREETA3 ${ }^{\mathrm{TM}}$ three-channel sensor to study, and demonstrated that phage-displayed antibodies ( $\mathrm{scFv}$ fusions to pIII ) can be used as the biorecognition element for specific and sensitive detection of L. monocytogenes.

Quantech, founded in 1991, is completing development of a relatively inexpensive multitest critical care diagnostic system based on SPR detection. Regardless, this is the first example of SPR immunoassay instrument specifically designated for medical analysis. In contrast to the BIAcore instruments, using prisms to couple the incident light to the gold sensing film, Quantech uses a grating surface coated with a thin layer of gold for its disposable. The first tests are likely to aid the diagnosis of heart attack patients [81].

Satio [82] synthesized a water-insoluble phospholipid polymer bearing a phenylboronic acid moiety (PMBV), which induces cell adhesion through a specific interaction with the glycoprotein, fibronectin. The binding affinity between fibronectin and the PMBV surface was estimated by SPR-670M.

Almost six years ago, Kinomics $\mathrm{GmbH}$ was founded with the aim to establish time and material saving methodologies in affinity-based biosensor. As a result, the Multi-Step Kinetics (MSK) invented by Kinomics was taken over in an exclusive cooperation by BIAcore AB (now part of GE Healthcare) in 2006, shortly after, marketed as Single-Cycle Kinetics (SCK), although much less flexible than MSK (what a comparative test may reveal). Since early 2006, already three papers [83-85] have been published that utilize Kinomics' parent-pending, time- and sample-saving MSK principle of unnecessary intermediate regeneration in affinity-based biosensor.

In 1995, the cuvette based SPR system of IBIS Technologies was launched. The instrument was compatible with the BIAcore sensor chip. In 1997, the IBIS II, a two-channel cuvette-based SPR instrument with autosampler operation, was introduced [86]. Following the merger with the sensor chip coating company Ssens BV in 1999, the development of an SPR imaging instrument was initiated at IBIS Technologies. In 2007, the development of the IBIS-iSPR instrument, with the scanning angle principle, resulted in the required reliability and accuracy for microarray imaging of multiple biomolecular interactions. Raz [87] examined the possibilities of implementing direct and competitive immunoassay formats for small and large molecule detection on a microarray, using IBIS imaging surface plasmon resonance (iSPR) system.

The Autolab SPR instrumentation helps the scientist to analyze biomolecular interactions in real time, without labeling requirements. García-Aljaro [88] used a twochannel microfluidic SPR sensor device (Windsor Scientific) to detect the presence of somatic coliphages, a group of bacteriophages that have been proposed as fecal pollution indicators in water, employed their host, Escherichia coli WG5, as a target for their selective detection.

The Institute of Electronics, Chinese Academy of Sciences, has manufactured SPR-2000 in 2001 [89]. Huang used SPR-2000 spectroscopy to monitor the regular growth of the multilayer films which electrostatic layer-by-layer (LbL) assembly by negatively charged 
citrate-stabilized platinum nanoparticles (Pt NPs) and positively charged [tetrakis $(N$-methylpyridyl) prophyrinato] cobalt [90].

However, from the description above, it is obvious to see that the major application of SPR sensor focus on studying the interactions between large biomolecules, small molecular dynamics is seldom monitored by conventional SPR technique because the changes in the refractive index resulted from the binding process of small molecules are often small. Therefore, direct assay of small molecules by SPR sensor in general is troublesome and at least tedious procedures have to be applied. Some methods have been used to improve the sensitivity of SPR sensor for detecting small molecules. For instance, employed polymers with high molecular weight as a transduction layer to increase the changes in the refractive index at the sensing interface triggered by small molecules [91], utilized the conformational change of macromolecules or proteins switched by small molecules to amplify the change of SPR signal [92,93], used of a high molecular weight ligand that competed with the small molecular weight analyte for receptor binding. Liu [94] detailed the incorporation of a water-soluble deep cavitand into a membrane bilayer assembled onto a nanoglassified surface for study of molecular recognition in a membrane-mimicking setting. Kawaguchi [95] developed a new immunosensor based on self-assembly chemistry for highly sensitive and label-free detection of TNT. In the past years, Au nanoparticles have been applied to enhance the sensitivity of SPR sensor to detect small molecules. The electronic coupling interaction between the localized surface plasmon of the $\mathrm{Au}$ nanoparticles and the surface plasmon wave associated with the SPR gold film enabled enhancing the shift of SPR angle. Matsui [96] prepared molecularly imprinted polymer gel with embedded gold nanoparticle on a gold substrate of a chip for a SPR sensor for fabricating an SPR sensitive to a low molecular weight analyte, TNT. The molecular imprinted polymer with immobilized Au nanoparticle exhibited selective binding of a small molecule accompanied by swelling, which caused the greater distance between the immobilized Au nanoparticles.

Sensitive detection of small molecules using SPR sensor presents significant challenges as the antigen cannot serve as a signal generator because of its low mass. Efficient binding of the target requires the binding event to be spaced from the sensor surface through a specialist linker conjugation. Intermediate linkers can be used to provide optimal antigen presentation in flowthrough assay format. The binding of the analyte in the presence of compounds under investigation in a concentration range is assayed. The resulting inhibition curves of the equilibrium SPR signal as function of the compound concentration can be analyzed to yield thermodynamic binding constants for the interaction in solution between analyte and the compounds under investigate. However, the combination of small molecules and the antibody which fixed on gold-chip is a very fast process, the whole combination process can't be achieved with ordinary means. Therefore, it is necessary to apply the time-resolved techniques to detect small molecular dynamics.

Tao [25] described a new SPR detection method that has been allowed to achieve an angular resolution of $10^{-5}$ $\operatorname{deg}\left(10^{-8}\right.$ RIU) and time response of $1 \mu \mathrm{s}$. The method uses a convergent beam focused onto a thin metal film, but the total internal reflection is collected by a bicell photodetector instead of a CCD or a LDA. The reflected light falling on the two cells of the photodetector is first balanced so that the SPR dip is located near the center of the photodetector. A small shift in the dip position causes an imbalance in the two cells which is detected as a change in the differential signal of the bicell photodetector. Because the ratio of the differential signal to the sum signal of the bicell photodetector is linearly proportional to the shift in the SPR angle and can be easily amplified without saturation problem, it provides an accurate detection of SPR.

Pettit [28] discussed a relatively simple method for time resolved detection of electrochemical effects using SPR under potentiodynamic condition. The SPR experiments are performed with a collimated laser beam at a fixed wavelength using the Kretshchmann configuration. The instrument uses a commonly available fast photodiode for signal detection, and has an angular resolution of $10^{-3} \mathrm{deg}$, a temporal resolution $(\sim 500 \mu \mathrm{s})$ better than or comparable to those of most published sensograms for commonly studied electrochemical and biological reactions. In their work, they examined the theoretical considerations of the collimated-light time resolved SPR technique. Using analytical formulas as well as numerical calculations for a six-phase configuration, they showed that the basic approach of that method is quite general, and is applicable to a large variety of experimental system. The transient SPR response of the electrode to voltage variations contains features of certain interfacial effects that cannot be detected using electrochemical measurements alone. This SPR technique is suitable for studying both faradaic and nonfaradaic reations.

Besides the laboratory time-resolved SPR (TR-SPR), Thermo FT-SPR 100 and Autolab ESPRIT (SPRINGLE) are the two most versatile TR-SPR commercial instruments on the market.

Department of molecular spectroscopy of Thermo 
Electron Corporation (Nicolet) in its past forty years Fourier transform infrared (FTIR) technology combined with the latest SPR patented technology (US Patent No. 6330062), introduced a new Fourier-transform surface plasmon resonance (FT-SPR) detector-SPR 100. FT-SPR system performs SPR detection by wavelength scanning in the near infra-red region. There are many benefits of FT-SPR detector. It has high sensitivity with capabilities include detection of film thickness changes of $<1 \mathrm{~A}^{\circ}$, the binding of small molecules to the immobilized proteins, and low affinity molecular interactions. This system has the greatest dynamic range of any other commercially available SPR systems. Operating from $\sim 12,000$ to 5,800 $\mathrm{cm}^{-1}$, the SPR 100 captures quantitative data for major surface changes as well as subtle ones. Besides, the application scope of this system is diverse. The broad scope is due to the combination of broad spectral range with broad incident light angles from $\sim 40^{\circ}-70^{\circ}$. Measurements can be made in liquid or in gas phases, and on metals or conducting metal oxides (CMOs), further expanding the usefulness of this system. Furthermore, the FT-IR spectrometer with the SPR 100 module provides fully functioning infrared spectroscopic capabilities that allow researchers to gain insight into the chemical information of the binding layers.

Applications of FT-SPR analysis include the quantitative characterization of protein-protein, protein-ligand and protein-nucleic acid interactions, antibody-antigen interactions, Langmuir-Blodgett films, self-assembled monolayers, organic thin films, etc. Frutos [97] described the application of SPR measurements to the study of ultrathin organic films adsorbed onto gold surfaces utilizing near-infrared (NIR) excitation from a Fourier transform (FT) spectrometer. Upon adsorption of a thin biopolymer film from solution, a shift in the minimum is observed that can be correlated to a film thickness using Fresnel calculations. FT-SPR using Au (111) chips modified by a 1,3-alternate calix[4]arene-crown- 6 derivative was proposed by Arena [98] as a method to detect $\mathrm{Cs}^{+}$at the $p p b$ level. Zhao [99] provided a new concept for designing an SWNT-induced DNA nanomachine and for the detection of i-motif DNA structure at $\mathrm{pH}$ 7.0. The folding and unfolding kinetics of the DNA nanomachine on gold surface were studied by FT-SPR. Three sensitive and original transduction techniques, polarization modulation-reflection absorption infrared spectroscopy (PMRAIRS), quartz crystal microbalance with dissipation measurements (QCM-D), and Fourier transform-surface plasmon resonance (FT-SPR), have been used by Boujday [100] to monitor the immobilization of anti-rabbit immunoglobulins (anti-rIgGs) and the detection of rIgGs on gold transducers. Their performances were compared after having checked that the layers adsorbed on the three different gold substrates were identical. Interestingly, the three techniques suggested that the antibody coverage got saturated for approximately $20 \mu \mathrm{g} / \mathrm{ml}$ in solution. In the very low concentration range $(1 \mu \mathrm{g} / \mathrm{ml})$, antibody binding was detected by the three techniques, but FTSPR leads to an intense signal with a wavenumber shift of approximately $30 \mathrm{~cm}^{-1}$; one may expect, by FT-SPR, a detection limit of the order of a few tenths of $\mu \mathrm{g} / \mathrm{ml}$.

The Autolab ESPRIT is a dual-channel system allows us to run multiple samples on a fully automated system, including sample recovery if required. With two channels, one can be used for sample measurement and the second as a reference for non-specific binding compensation temperature. The Autolab SPRINGLE is a single-channel unit with a compact design, making it an affordable alternative for research chemists who want a superior measurement technique. The Autolab SPR systems perform angular scanning SPR detection in the angle range of $68^{\circ}$ to $78^{\circ}$ with the dynamic range resolution $<5 \times 10^{-4}$. The most prominent advantage of the Autolab SPR systems is high measuring frequency- $76 \mathrm{~Hz}$ which makes it suitable for studying the dynamics of biomolecular interactions and drugs-proteins interactions.

SPR technique has become a standard tool in life sciences and pharmaceutical research laboratories. It is essential to study and characterize molecular interactions, explore the structure-function relationships of biomolecules and understand biological systems in life sciences. The Autolab SPR system also offers a unique ability to combine both SPR and electrochemistry measurement, including cyclic voltammetry, chrono-amperometry as well as impedance spectroscopy. The new aspect of this analysis, simultaneous electrochemical analysis also plays a unique role in the better understanding of the nature of these molecular interactions. In addition, kinetic analysis software of the Autolab SPR system can be used to automatically determine kinetic rate constants, affinity constant and thermodynamic parameter. Dutra [101] developed a SPR sensor in real time to detect the biomarker-cardiac troponin (cTnT) on Autolab SPIRIT. An Autolab potentiostat/galvanostat (PGSTAT30, Echo Chemie B.V., the Netherlands) was connected to the Autolab SPRINGLE system to enable electrochemical modulation during in situ electrochemical-optical measurements. $\mathrm{Hu}[102]$ used it to in situ investigate the electrochemical growth process of poly(pyrrole-co-pyrrole propylic acid) ( $\mathrm{PPy} / \mathrm{PPa})$ composite films. The SPR and electrochemical signals were recorded simultaneously during the first cycle. In the electropolymerization process, cyclic voltammetry at scan rate of $100 \mathrm{mV} / \mathrm{s}$. The SPR and electrochemical signals could record simultaneously at a high scan rate- $100 \mathrm{mV} / \mathrm{s}$, which indicated the measuring frequency of Autolab SPR system was very 
high compared with other apparatus [91,103]. Hu [104] also used it to study the assembly process of multiwalled carbon nanotubes (MWCNTs) quantitatively on an alkanethiol self-assembled monolayer (SAM) surface. And they further in situ investigated protein attachment on the MWCNT surface and its sensing application quantitatively.

\section{Introduction of a new Commercial Time-Resolved Surface Plasmon Resonance (TR-SPR) Spectroscopy}

The Autolab SPR system offers a unique ability to combine both SPR spectroscopy and electrochemistry system. The SPR technology can combine with not only electrochemistry methods (stripping voltammetry [105,106], cyclic voltammetry (CV) [107-109], electrochemical impedance spectroscopy (EIS) [110]), but also other analysis techniques, such as spectral analysis (fluorescence spectra [111-113], infrared spectrum [114,115], interferometry [116,117]), mass spectrometry (MS) [118, 119], atomic force microscope (AFM) [120] and quartz crystal microbalance (QCM) [121,122]. The combination of SPR and electrochemistry, often called electrochemical surface plasmon resonance (EC-SPR), has been widely used. The electrochemical and SPR signals can be detected simultaneously, which is the most significant advantage of EC-SPR. The SPR sensor is extremely sensitive to the concentration variety of material adsorbed on the sensor chip surface and redox substances dissolved in the electrolyte. Meanwhile, the Faraday current is proportional to the concentration gradient of the electrode surface. Therefore, EC-SPR can supply some information about electrochemical reaction process of a wide range in electrochemical fields. It can be used to characterize the interface between the electrode and solution [50,123], study the doping-dedoping process [124-126] and the adsorption-desorption reactions [107, $127,128]$, detect trace substance $[105,129,130]$, determinate the film thickness and permittivity [131-133]. However, the combination of electrochemistry and SPR requires SPR spectroscopy has high time resolution.

From the introduction above, it is necessary to build TR-SPR spectrometer with high time resolution, which can not only study small molecular dynamics, but also combine with electrochemistry for electrochemical reaction process studying. Consequently, the application scope of SPR sensor can greatly expand. However, only two commercial TR-SPR instruments are available right at present, Thermo FT-SPR 100 and Autolab ESPRIT (SPRINGLE). Unfortunately, the high-priced instruments are not suitable for wide applications in laboratories. Therefore, a novel commercial TR-SPR spectrome- ter is introduced with a high angular resolution $\left(0.001^{\circ}\right)$ and a temporal resolution $(<0.1 \mathrm{~ms})$. The time resolution is better than or comparable to those of most published sensograms for commonly studied electrochemical and biological reactions.

There are angular, wavelength, intensity, phase and polarization modulation SPR sensors. Moreover, the major points of the new commercial TR-SPR development were around angular modulation and intensity modulation. These two methods are realized as follows:

In SPR sensor with angular modulation a monochromatic light wave excites a surface plasmon. The strength of coupling between the incident wave and the surface plasmon is observed at multiple angles of incidence of the light wave and the angle of incidence yielding the strongest coupling is measured and used as a sensor output. The sensor output can be calibrated to refractive index.

SPR sensors with intensity modulation are based on measuring the strength of the coupling between the incident light wave and a surface plasmon at a single angle of incidence. And the intensity of light wave serves as a sensor output.

This new generation time-resolved surface plasmon resonance (TR-SPR) spectrometer is shown in Figure 2(a). The method used for surface plasmon detection was ATR spectrometer. Surface plasmon spectroscopic data were collected using Kretschmann optical configuration, as shown schematically in Figure 2(b). The evaporated gold film (thickness $46 \mathrm{~nm}$ ) on the glass microscope slide was used as surface plasmon medium. The evaporated chromium as an adhesion layer (thickness $1.5 \mathrm{~nm}$ ) was used to avoid the peeling of gold during SPR experiments. The glass slide with the evaporated gold on the opposite side was pressed on a $\mathrm{ZK}_{7}$ cylindrical glass prism $(\mathrm{n}=1.6130)$ via an index matching liquid. The gold surface of the slide was covered with silicone rubber sheet with a hole for the electrolyte contact. The linearly p-polarized light from a laser diode $(650 \mathrm{~nm}, 5$ $\mathrm{mW}$ ) was directly through the prism onto the gold chip. The intensity of the reflected light was measured by a two current photoelectric position transducer with a 30

$\mathrm{m}$ gap. In SPR measurements, two modes, angular modulation and intensity modulation, record the shift of resonance minimum angle and the "light changes" at a fixed angle. The two modes can be chosen to study different surface processes. The "light changes" expressed $\mathrm{A}+\mathrm{B}$ or $(\mathrm{A}-\mathrm{B}) /(\mathrm{A}+\mathrm{B}), \mathrm{A}$ and $\mathrm{B}$ represented the light intensity collected by the two photovoltaic cells, respecitvely. The ratio of the differential signal to the sum signal of the bicell photodetector, $(\mathrm{A}-\mathrm{B}) /(\mathrm{A}+\mathrm{B})$, is linearly proportional to the SPR angle shift, it provides an accurate measurement of shift in surface plasmon 
resonance angle caused by the adsorption of molecules onto the metal films or by conformational changes in the adsorbed molecules [25].

There are several advantages of this TR-SPR spectrometer. The apparatus has high precision with the accuracy of resonance angle measurement is $0.001^{\circ}$, which includes the mechanical correction. Meanwhile, the time resolution of the TR-SPR system is extremely high. The SPR data collection rate is less than $0.1 \mathrm{~ms}(10 \mathrm{kHz})$ in the fixed angle mode, which is much faster than the Autolab SPR system besides other SPR systems. The application scope can greatly be expanded by the high time resolution. This TR-SPR spectroscopy can be easily used to explore the assemble dynamic of mercaptopropionic acid on the gold-chip, as shown as an example in Figure 3(a). The morphine detection is shown in Figure 3(b). Figure 3(c) shows the polyaniline characterization with simultaneously cyclic voltammetry of high scan rate and fixed angle SPR mode. Another advantage is such TR-SPR spectrometer has a wide measuring range. The angle scan range of the mechanical scanning system is $50^{\circ} \sim 72^{\circ}$, and the refractive index range of the response measurement sample is about $1.00 \sim 1.40$.

Owing to the high time resolution, the new TR-SPR system offers an possibility to combine SPR with electrochemistry measurement, not only the conventional electrochemical techniques (e.g. cyclic voltammetry, linear sweep voltammetry, open circuit potential-time, amperometric i-t curve, etc), but also make it possible for the transient electrochemical techniques (e.g. chronoamperometry, chronocoulometry, differential pulse voltammetry, normal pulse voltammetry, square wave voltammetry, etc) with electrochemical current detection rate

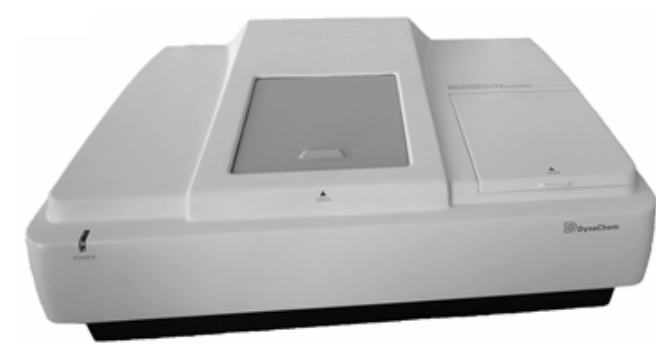

(a)

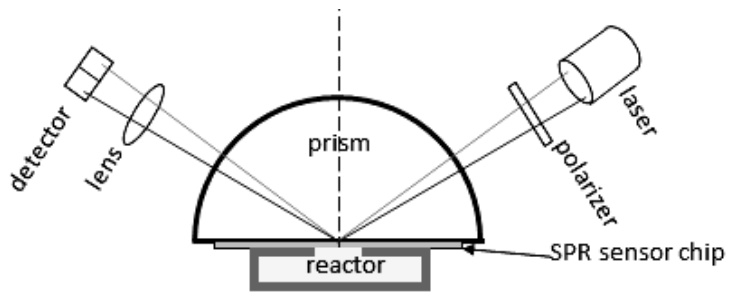

(b)

Figure 2. The picture (a) and the configuration schematic diagram (b) of the new commercial TR-SPR spectrometer.

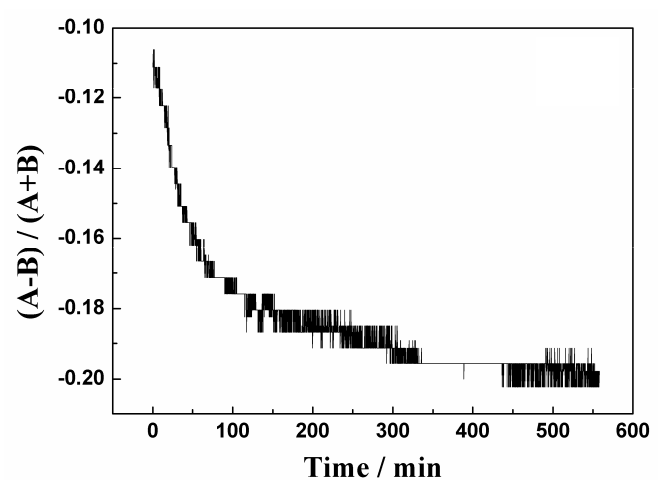

(a)

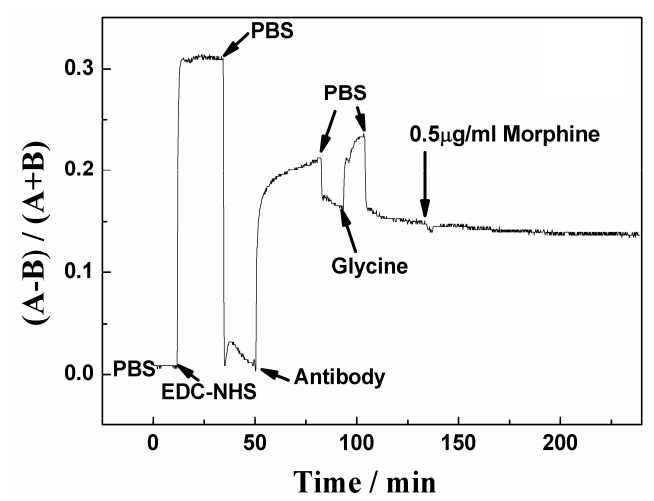

(b)

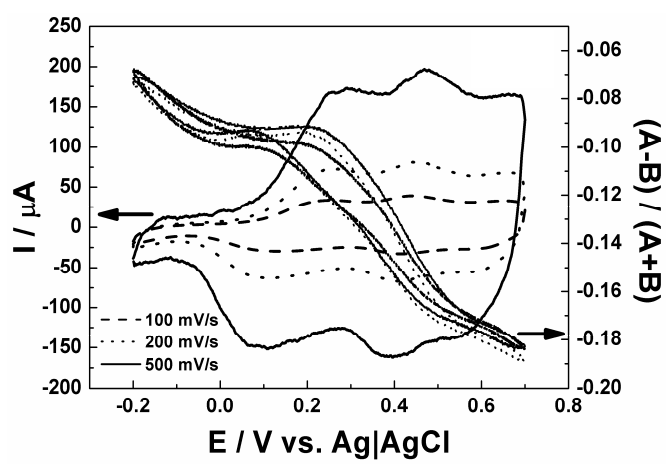

(c)

Figure 3. The assembly dynamics of $5 \mathrm{mM}$ mercaptopropionic acid in ethanol absorbed on the gold chip (a), morphine detection on the fixed angle model (b), polyaniline characterization at different scan rate (c).

greater than $1 \mathrm{kHz}$. In order to acquire more information from various systems, the single-wavelength laser will be replaced by three-wavelength laser $(532 \mathrm{~nm}, 660 \mathrm{~nm}$ and $780 \mathrm{~nm}$ ) in the next plan. It is believed that with the introduction of the new TR-SPR instrument and a series of novel sensor surfaces, the impact of SPR sensors on molecular interaction studies will continue to grow. With improved experimental design and advanced data analysis methods, high-quality data for the determination of kinetic parameters of molecular interactions phenomena 
can be obtained. These data promise additional insights into the mechanisms of molecular binding events, which will be important for function-regulatory protein interactions studies in order to unravel the exciting processes in living species. In addition, such a TR-SPR sensor system hold potential for many other applications of paramount importance, including detection of contaminants related to environmental monitoring, human health indicators for medical diagnostics, foodborne pathogens and toxins implicated in food safety and security.

\section{Conclusions}

Over the past ten years, surface plasmon resonance (SPR) sensor technology has made great strides, and a large number of SPR sensor platforms, biomolecular recognition elements, measurement formats have been developed. From the development of SPR sensors and commercial SPR instruments, it is obvious to see that small molecular dynamics is seldom detected by conventional SPR technique because the refractive index changes resulted from the binding process of small molecules are often small and the binding process is very fast. Although some methods have been used to improve the sensitivity of SPR for detecting small molecules, direct assay of small molecules by SPR sensor in general is troublesome and at least tedious procedures have to be applied. However, the new commercial TR-SPR spectroscopy can directly detect small molecular assembly dynamics due to its high time resolution.

Major SPR sensor application areas include investigating biomolecular interactions and binding properties, detection of biological and chemical analytes, environmental monitoring, food safety and medical diagnostics. Applications in these areas present unique challenges and impose special requirement on analytical technologies, such as pharmaceutical research needs laboratory-based high-throughput systems with high sensitivity to facilitate parallel screening, environmental monitoring would benefit from detection systems which could be deployed in the field for continuous monitoring and from mobile systems enabling fast identification of environmental threat. Hence, there is a trend to build the SPR instruments to meet diverse requirements. The new commercial TR-SPR spectroscopy offers a possibility to combine SPR with transient electrochemical techniques, which broadens the application scope of SPR on a large degree.

\section{Acknowledgements}

The authors are most grateful to the NSFC (No.20827004), Department of Science and Technology of Jilin Province (No.20080518), and Chinese Academy of Sciences (No. YZ200906 and YZ2010018) for their financial support.

\section{References}

[1] N. Blow, "Proteins and proteomics: life on the surface," Nature Methods, Vol. 6, No. 5, May 2009, pp. 389-392.

[2] Y. Liu, Y. Dong, J. Jauw, M. J. Linman and Q. Cheng, "Highly Sensitive Detection of Protein Toxins by Surface Plasmon Resonance with Biotinylation-Based Inline Atom Transfer Radical Polymerization Amplification," Analytical Chemistry, Vol. 82, No. 9, April 2010, pp. 3679-3685.

[3] C. M. Cuerrier, V. Chabot, S. Vigneux, V. Aimez, E. Escher, F. Gobeil, P. G. Charette and M. Grandbois, "Surface Plasmon Resonance Monitoring of Cell Monolayer Integrity: Implication of Signaling Pathways Involved in Actin-Driven Morphological Remodeling," Cellular and Molecular Bioengineering, Vol. 1, No. 4, December 2008, pp. 229-239.

[4] S. H. Lee, H. J. Ko and T. H. Park, "Real-Time Monitoring of Odorant-Induced Cellular Reactions Using Surface Plasmon Resonance," Biosensors \& Bioelectronics, Vol. 25, No. 1, June 2009, pp. 55-60.

[5] A. L. Plant, M. Brighamburke, E. C. Petrella and D. J. Oshannessy, "Phospholipid/alkanethiol bilayers for cellsurface receptor studies by surface plasmon resonance," Analytical Biochemistry, Vol. 226, No. 2, April 1995, pp. 342-348

[6] J. Chen, K. Carey and P. J. Godowski, "Identification of Gas6 as a Ligand for Mer, a Neural Cell Adhesion Molecule Related Receptor Tyrosine Kinase Implicated in Cellular Transformation," Oncogene, Vol. 14, No. 17, May 1997, pp. 2033-2039.

[7] G. E. de Kloe, K. Retra, M. Geitmann, P. Kallblad, T. Nahar, R. van Elk, A. B. Smit, J. E. van MuijlwijkKoezen, R. Leurs, H. Irth, U. H. Danielson and I. J. P. de Esch, "Surface Plasmon Resonance Biosensor Based Fragment Screening Using Acetylcholine Binding Protein Identifies Ligand Efficiency Hot Spots (LE Hot Spots) by Deconstruction of Nicotinic Acetylcholine Receptor alpha 7 Ligands," Journal of Medicinal Chemistry, Vol. 53, No. 19, September 2010, pp. 7192-7201.

[8] S. T. R. Walsh, "A Biosensor Study Indicating That Entropy, Electrostatics, and Receptor Glycosylation Drive the Binding Interaction between Interleukin-7 and Its Receptor," Biochemistry, Vol. 49, No. 40, September 2010, pp. 8766-8778.

[9] M. Veiseh, M. H. Zareie and M. Q. Zhang, "Highly Selective Protein Patterning on Gold-Silicon Substrates for Biosensor Applications," Langmuir, Vol. 18, No. 17, July 2002, pp. 6671-6678.

[10] M. Zayats, O. A. Raitman, V. I. Chegel, A. B. Kharitonov and I. Willner, "Probing Antigen-Antibody Binding Processes by Impedance Measurements on Ion-Sensitive Field-Effect Transistor Devices and Complementary Surface Plasmon Resonance Analyses: Development of Cholera Toxin Sensors," Analytical Chemistry, Vol. 74, No. 18, September 2002, pp. 4763-4773.

[11] J. M. Lee, H. K. Park, Y. Jung, J. K. Kim, S. O. Jung and B. H. Chung, "Direct Immobilization of Protein G Vari- 
ants with Various Numbers of Cysteine Residues on a Gold Surface," Analytical Chemistry, Vol. 79, No. 7, March 2007, pp. 2680-2687.

[12] C. Ayela, F. Roquet, L. Valera, C. Granier, L. Nicu and M. Pugniere, "Antibody-Antigenic Peptide Interactions Monitored by SPR and QCM-D - A Model for SPR Detection of IA-2 Autoantibodies in Human Serum," Biosensors \& Bioelectronics, Vol. 22, No. 12, June 2007, pp. 3113- 3119.

[13] L. C. Su, R. C. Chen, Y. C. Li, Y. F. Chang, Y. J. Lee, C. C. Lee and C. Chou, "Detection of Prostate-Specific Antigen with a Paired Surface Plasma Wave Biosensor," Analytical Chemistry, Vol. 82, No. 9, April 2010, pp. 3714-3718.

[14] A. Singhal, C. A. Haynes and C. L. Hansen, "Microfluidic Measurement of Antibody-Antigen Binding Kinetics from Low-Abundance Samples and Single Cells," Analytical Chemistry, Vol. 82, No. 20, September 2010, pp. 8671-8679.

[15] H. A. Craig-Barnes, B. S. Doumouras and N. Palaniyar, "Surfactant Protein D Interacts with alpha(2)-Macroglobulin and Increases Its Innate Immune Potential," Journal of Biological Chemistry, Vol. 285, No. 18, April 2010, pp. 13461-13470.

[16] D. K. Cole, E. S. J. Edwards, K. K. Wynn, M. Clement, J. J. Miles, K. Ladell, J. Ekeruche, E. Gostick, K. J. Adams, A. Skowera, M. Peakman, L. Wooldridge, D. A. Price and A. K. Sewell, "Modification of MHC Anchor Residues Generates Heteroclitic Peptides That Alter TCR Binding and T Cell Recognition," Journal of Immunology, Vol. 185, No. 4, August 2010, pp. 2600-2610.

[17] Y. Teramura, H. Iwata, "Label-Free Immunosensing for Alpha-Fetoprotein in Human Plasma Using Surface Plasmon Resonance," Analytical Biochemistry, Vol. 365, No. 2, June 2007, pp. 201-207.

[18] V. Kumar, M. I. Hassan, A. K. Singh, S. Dey, T. P. Singh and S. Yadav, "Strategy for Sensitive and Specific Detection of Molecular Forms of PSA Based on 2DE and Kinetic Analysis: A Step Towards Diagnosis of Prostate Cancer," Clinica Chimica Acta, Vol. 403, No. 1-2, May 2009, pp. 17-22.

[19] N. Debotton, H. Zer, M. Parnes, O. Harush-Frenkel, J. Kadouche and S. Benita, "A Quantitative Evaluation of the Molecular Binding Affinity between a Monoclonal Antibody Conjugated to a Nanoparticle and an Antigen by Surface Plasmon Resonance," European Journal of Pharmaceutics and Biopharmaceutics, Vol. 74, No. 2, February 2010, pp. 148-156.

[20] H. Nishijima, A. Kosaihira, J. Shibata and T. Ona, "Development of Signaling Echo Method for Cell-based Quantitative Efficacy Evaluation of Anti-cancer Drugs in Apoptosis without Drug Presence Using High-precision Surface Plasmon Resonance Sensing," Analytical Sciences, Vol. 26, No. 5, May 2010, pp. 529-534.

[21] I. Navratilova, A. L. Hopkins, "Fragment Screening by Surface Plasmon Resonance," ACS Medicinal Chemistry Letters, Vol. 1, No. 1, February 2010, pp. 44-48.

[22] R. S. Moirangthem, Y. C. Chang, S. H. Hsu and P. K.
Wei, "Surface Plasmon Resonance Ellipsometry Based Sensor for Studying Biomolecular Interaction," Biosensors \& Bioelectronics, Vol. 25, No. 12, August 2010, pp. 2633-2638.

[23] N. Tuleuova, C. N. Jones, J. Yan, E. Ramanculov, Y. Yokobayashi and A. Revzin, "Development of an Aptamer Beacon for Detection of Interferon-Gamma," Analytical Chemistry, Vol. 82, No. 5, March 2010, pp. 1851-1857.

[24] M. Geitmann, K. Retra, G. E. de Kloe, E. Homan, A. B. Smit, I. J. P. de Esch and U. H. Danielson, "Interaction Kinetic and Structural Dynamic Analysis of Ligand Binding to Acetylcholine-Binding Protein," Biochemistry, Vol. 49, No. 37, September 2010, pp. 8143-8154.

[25] N. J. Tao, S. Boussaad, W. L. Huang, R. A. Arechabaleta and J. D'Agnese, "High Resolution Surface Plasmon Resonance Spectroscopy," Review of Scientific Instruments, Vol. 70, No. 12, August 1999, pp. 4656-4660.

[26] S. Boussaad, J. Pean and N. J. Tao, "High-Resolution Multiwavelength Surface Plasmon Resonance Spectroscopy for Probing Conformational and Electronic Changes in Redox Proteins," Analytical Chemistry, Vol. 72, No. 1, January 2000, pp. 222-226.

[27] J. E. Garland, K. A. Assiongbon, C. M. Pettit and D. Roy, "Surface Plasmon Resonance Transients at an Electrochemical Interface: Time Resolved Measurements Using A Bicell Photodiode," Analytica Chimica Acta, Vol. 475, No. 1-2, January 2003, pp. 47-58.

[28] C. M. Pettit, K. A. Assiongbon, J. E. Garland and D. Roy, "Time Resolved Detection of Electrochemical Effects by Surface Plasmon Resonance Measurements: A Simple Technique Using a Large Area Single Cell Photodiode," Sensors and Actuators B: Chemical, Vol. 96, No. 1-2, July 2003, pp. 105-113.

[29] R. J. Green, J. Davies, M. C. Davies, C. J. Roberts and S. J. B. Tendler, "Surface Plasmon Resonance for Real Time in Situ Analysis of Protein Adsorption to Polymer Surfaces," Biomaterials, Vol. 18, No. 5, March 1997, pp. 405-413.

[30] J. Homola, S. S. Yee and G. Gauglitz, "Surface Plasmon Resonance Sensors: Review," Sensors and Actuators BChemical, Vol. 54, No. 1-2, January 1999, pp. 3-15.

[31] R. L. Rich, D. G. Myszka, "Advances in surface plasmon resonance biosensor analysis," Current Opinion in Biotechnology, Vol. 11, No. 1, February 2000, pp. 54-61.

[32] K. Johansen, H. Arwin, I. Lundstrom and B. Liedberg, "Imaging Surface Plasmon Resonance Sensor Based on Multiple Wavelengths: Sensitivity Considerations," Review of Scientific Instruments, Vol. 71, No. 9, June 2000, pp. 3530-3538.

[33] C. L. Baird, D. G. Myszka, "Current and Emerging Commercial Optical Biosensors," Journal of Molecular Recognition, Vol. 14, No. 5, October 2001, pp. 261-268.

[34] S. Dong, X. Chen, "Some new aspects in biosensors," Reviews in Molecular Biotechnology, Vol. 82, No. 4, February 2002, pp. 303-323.

[35] E. Kretschmann, H. Raether, "Radiative Decay of Non- 
radiative Surface Plasmons Excited by Light," Zeitschrift fur Naturforschung part A-Astrophysik physik und physikalische chemie Vol. 23A, 1968, pp. 2135-2136.

[36] A. Otto, "Excitation of Nonradiative Surface Plasma Waves in Silver by the Method of Frustrated Total Reflection," Zeitschrift für Physik A Hadrons and Nuclei, Vol. 216, No. 4, July 1968, pp. 398-410.

[37] J. Homola, I. Koudela and S. S. Yee, "Surface Plasmon Resonance Sensors Based on Diffraction Gratings and Prism Couplers: Sensitivity Comparison," Sensors and Actuators B: Chemical, Vol. 54, No. 1-2, January 1999, pp. 16-24. doi:org/10.1016/S0925-4005(98)00322-0

[38] J. Homola, "Surface Plasmon Resonance Based Sensors," Springer, Verlag Berlin Heidelberg, 2006, pp. 26-29.

[39] J. Homola, "Present and Future of Surface Plasmon Resonance Biosensors," Analytical and Bioanalytical Chemistry, Vol. 377, No. 3, October 2003, pp. 528-539. doi:org/10.1007/s00216-003-2101-0

[40] A. N. Grigorenko, P. I. Nikitin and A. V. Kabashin, "Phase Jumps and Interferometric Surface Plasmon Resonance Imaging," Applied Physics Letters, Vol. 75, No. 25, October 1999, pp. 3917-3919. doi:org/10.1063/1.125493

[41] L. I. Goray, J. F. Seely, "Efficiencies of Master, Replica, and Multilayer Gratings for the Soft-X-Ray-Extreme-Ultraviolet Range: Modeling Based on the Modified Integral Method and Comparisons with Measurements," Applied Optics, Vol. 41, No. 7, March 2002, pp. 1434-1445. doi:org/10.1364/AO.41.001434

[42] R. W. Wood, "On a Remarkable Case of Uneven Distribution of Light in a Diffraction Grating Spectrum," Philosophical Magazine, Vol. 4, No. 21, September 1902, pp. 396-402.

[43] R. W. Wood, "Diffraction Gratings with Controlled Groove form and Abnormal Distribution of intensity," Philosophical Magazine, Vol. 23, No. 134, February 1912, pp. 310-317.

[44] U. Fano, "The Theory of Anomalous Diffraction Gratings and of Quasi-Stationary Waves on Metallic Surfaces (Sommerfeld's Waves)," Journal of Optical Society of America, Vol. 31, No. 3, March 1941, pp. 213-222. doi:org/10.1364/JOSA.31.000213

[45] R. H. Ritchie, "Plasma Losses by Fast Electrons in Thin Films," Physical Review, Vol. 106, No. 5, February 1957, pp. 874-881. doi:org/10.1103/PhysRev.106.874

[46] C. J. Powell, J. B. Swan, "Origin of the Characteristic Electron Energy Losses in Aluminum," Physical Review, Vol. 115, No. 4, August 1959, pp. 869-875. doi:org/10.1103/PhysRev.115.869

[47] E. A. Stern, R. A. Ferrell, "Surface Plasma Oscillations of a Degenerate Electron Gas," Physical Review, Vol. 120, No. 1, October 1960, pp. 130-136. doi:org/10.1103/PhysRev.120.130

[48] E. Kretschmann, "Die Bestimmung Optischer Konstanten von Metallen durch Anregung von Oberflächenplasmaschwingungen," Zeitschrift für Physik A Hadrons and
Nuclei, Vol. 241, No. 4, September 1971, pp. 313-324.

[49] J. G. Gordon Ii, J. D. Swalen, "The effect of thin organic films on the surface plasma resonance on gold," Optics Communications, Vol. 22, No. 3, September 1977, pp. 374-376. doi:org/10.1016/S0030-4018(97)90032-8

[50] J. G. Gordon Ii, S. Ernst, "Surface plasmons as a probe of the electrochemical interface," Surface Science, Vol. 101, No. 1-3, December 1980, pp. 499-506. doi:org/10.1016/0039-6028(80)90644-5

[51] C. Nylander, B. Liedberg and T. Lind, "Gas Detection by Means of Surface Plasmon Resonance," Sensors and Actuators, Vol. 3, July 1982-1983, pp. 79-88. doi:org/10.1016/0250-6874(82)80008-5

[52] B. Liedberg, C. Nylander and I. Lunström, "Surface Plasmon Resonance for Gas Detection and Biosensing," Sensors and Actuators, Vol. 4, June 1983, pp. 299-304. doi:org/10.1016/0250-6874(83)85036-7

[53] K. Tiefenthaler, W. Lukosz, "Integrated Optical Switches and Gas Sensors," Optics Letters, Vol. 9, No. 4, April 1984, pp. 137-139. doi:org/10.1364/OL.9.000137

[54] D. C. Cullen, R. G. W. Brown and C. R. Lowe, "Detection of Immuno-Complex Formation Via Surface Plasmon Resonance on Gold-Coated Diffraction Gratings,' Biosensors, Vol. 3, No. 4, November 1987, pp. 211-225.

[55] M. J. Jory, P. S. Vukusic and J. R. Sambles, "Development of a Prototype Gas Sensor Using Surface Plasmon Resonance on Gratings," Sensors and Actuators B: Chemical, Vol. 17, No. 3, February 1994, pp. 203-209. doi:org/10.1016/0925-4005(93)00871-U

[56] R. Karlsson, A. Michaelsson and L. Mattsson, "Kinetic Analysis of Monoclonal Antibody-Antigen Interactions with a New Biosensor Based Analytical System," Journal of Immunological Methods, Vol. 145, No. 1-2, December 1991, pp. 229-240. doi:org/10.1016/0022-1759(91)90331-9

[57] L. G. Fägerstam, Å. Frostell-Karlsson, R. Karlsson, B. Persson and I. Rönnberg, "Biospecific Interaction Analysis Using Surface Plasmon Resonance Detection Applied to Kinetic, Binding Site and Concentration Analysis," Journal of Chromatography A, Vol. 597, No. 1-2, April 1992, pp. 397-410.

[58] R. C. Jorgenson, S. S. Yee, "A Fiber-Optic Chemical Sensor Based on Surface Plasmon Resonance," Sensors and Actuators B: Chemical, Vol. 12, No. 3, April 1993, pp. 213-220. doi:org/10.1016/0925-4005(93)80021-3

[59] P. I. Nikitin, A. A. Beloglazov, "A Multi-Purpose Sensor Based on Surface Plasmon Polariton Resonance in a Schot- tky Structure," Sensors and Actuators A: Physical, Vol. 42, No. 1-3, April 1994, pp. 547-552. doi:org/10.1016/0924-4247(94)80051-0

[60] S. G. Nelson, K. S. Johnston and S. S. Yee, "High Sensitivity Surface Plasmon Resonace Sensor Based on Phase Detection," Sensors and Actuators B: Chemical, Vol. 35, No. 1-3, September 1996, pp. 187-191. doi:org/10.1016/S0925-4005(97)80052-4

[61] P. I. Nikitin, A. A. Beloglazov, M. V. Valeiko, J. A. Creighton, A. M. Smith, N. A. J. M. Sommerdijk and J. D. 
Wright, "Silicon-based surface plasmon resonance chemical sensors," Sensors and Actuators B: Chemical, Vol. 38, No. 1-3, January-February 1997, pp. 53-57. doi:org/10.1016/S0925-4005(97)80171-2

[62] A. V. Kabashin, P. I. Nikitin, "Surface Plasmon Resonance Interferometer for Bio- and Chemical-Sensors," Optics Communications, Vol. 150, No. 1-6, May 1998, pp. 5-8.

[63] H. P. Ho, W. W. Lam and S. Y. Wu, "Surface Plasmon Resonance Sensor Based on the Measurement of Differential Phase," Review of Scientific Instruments, Vol. 73, No. 10, October 2002, pp. 3534-3539. doi:org/10.1063/1.1502016

[64] C.-M. Wu, S.-F. Joe and L.-B. Chang, "Interferometric Sensors Based on Surface Plasmon Resonance," Optical Fibers and Sensors for Medical Applications II, Vol. 4616, San Jose, January 2002, pp. 64-72.

[65] C.-M. Wu, Z.-C. Jian, S.-F. Joe and L.-B. Chang, "High-Sensitivity Sensor Based on Surface Plasmon Resonance and Heterodyne Interferometry," Sensors and Actuators B: Chemical, Vol. 92, No. 1-2, July 2003, pp. 133-136. doi:org/10.1016/S0925-4005(03)00157-6

[66] S. Y. Wu, H. P. Ho, W. C. Law, Chinlon Lin and S. K. Kong, "Highly Sensitive Differential Phase-Sensitive Surface Plasmon Resonance Biosensor Based on the Mach- Zehnder Configuration," Optics Letters, Vol. 29, No. 20, October 2004, pp. 2378-2380. doi:org/10.1364/OL.29.002378

[67] H. P. Ho, W. C. Law, S. Y. Wu, C. Lin and S. K. Kong, "Real-Time Optical Biosensor Based on Differential Phase Measurement of Surface Plasmon Resonance," Biosensors and Bioelectronics, Vol. 20, No. 10, April 2005, pp. 2177-2180. doi:org/10.1016/j.bios.2004.09.011

[68] U. Jonsson, L. Fagerstam, B. Ivarsson, B. Johnsson, R. Karlsson, K. Lundh, S. Lofas, B. Persson, H. Roos, I. Ronnberg, S. Sjolander, E. Stenberg, R. Stahlberg, C. Urbaniczky, H. Ostlin and M. Malmqvist, "Real-time Biospecific Interaction Analysis Using Surface-Plasmon Resonance and a Sensor Chip Technology," Biotechniques, Vol. 11, No. 5, November 1991, pp. 620-622, 624-627.

[69] A. B. Goldfine, D. C. Simonson, F. Folli, E. Patti and C. $\mathrm{R}$. Kahn, "In vivo and in vitro Studies of Vanadate in Human and Rodent Diabetes Mellitus," Molecular and Cellular Biochemistry, Vol. 153, No. 1-2, December 1995, pp. 217-231. doi:org/10.1007/BF01075941

[70] A. B. Goldfine, D. C. Simonson, F. Folli, M. E. Patti and C. R. Kahn, "Metabolic Effects of Sodium Metavanadate in Humans with Insulin-Dependent and Noninsulin-DePendent-Diabetes-Mellitus in-vivo and in-vitro Studies," Journal of Clinical Endocrinology \& Metabolism, vol. 80, no. 11, November 1995, pp. 3311-3320. doi:org/10.1210/jc.80.11.3311

[71] R. Karlsson and R. Stahlberg, "Surface Plasmon Resonance Detection and Multispot Sensing for Direct Monitoring of Interactions Involving Low-Molecular-Weight Analytes and for Determination of Low Affinities," Ana- lytical Biochemistry, Vol. 228, No. 2, July 1995, pp. 274-280.

[72] H. Kobayashi, T. Endo, N. Ogawa, H. Nagase, M. Iwata and H. Ueda, "Evaluation of the Interaction between [beta]-Cyclodextrin and Psychotropic Drugs by Surface Plasmon Resonance Assay with a Biacore $\AA$ System," Journal of Pharmaceutical and Biomedical Analysis, Vol. 54, No. 1, January 2011, pp. 258-263. doi:org/10.1016/j.jpba.2010.08.012

[73] G. Papalia, D. Myszka, "Exploring Minimal Biotinylation Conditions for Biosensor Analysis Using Capture Chips," Analytical Biochemistry, Vol. 403, No. 1-2, August 2010, pp. 30-35. doi:org/10.1016/j.ab.2010.03.044

[74] J. M. Glück, B. W. Koenig and D. Willbold, "Nanodiscs Allow the Use of Integral Membrane Proteins as Analytes in Surface Plasmon Resonance Studies," Analytical Biochemistry, Vol. 408, No. 1, January 2011, pp. 46-52. doi:org/10.1016/i.ab.2010.08.028

[75] R. Patel, B. A. Andrien Jr, "Kinetic Analysis of a Monoclonal Therapeutic Antibody and Its Single-Chain Homolog by Surface Plasmon Resonance," Analytical Biochemistry, Vol. 396, No. 1, January 2010, pp. 59-68. doi:org/10.1016/j.ab.2009.08.034

[76] L. A. Chtcheglova, M. Vogel, H. J. Gruber, G. Dietler and A. Haeberli, "Kinetics of the INTERACTION of DesAABB-Fibrin Monomer with Immobilized Fibrinogen," Biopolymers, Vol. 83, No. 1, April 2006, pp. 69-82.

[77] C. Natori, J. I. Kim, S. H. Bhoo, Y. J. Han, H. Hanzawa, M. Furuya and P. S. Song, "Differential Interactions of Phytochrome A (Pr vs. Pfr) with Monoclonal Antibodies Probed by a Surface Plasmon Resonance Technique," Photochemical \& Photobiological Sciences, Vol. 6, No. 1, January 2007, pp. 83-89.

[78] J. Melendez, R. Carr, D. U. Bartholomew, K. Kukanskis, J. Elkind, S. Yee, C. Furlong and R. Woodbury, "A Commercial Solution for Surface Plasmon Sensing," Sensors and Actuators B: Chemical, Vol. 35, No. 1-3, September 1996, pp. 212-216. doi:org/10.1016/S0925-4005(97)80057-3

[79] J. Melendez, R. Carr, D. Bartholomew, H. Taneja, S. Yee, C. Jung and C. Furlong, "Development of a Surface Plasmon Resonance Sensor for Commercial Applications," Sensors and Actuators B-Chemical, Vol. 39, No. 1-3, March-April 1997, pp. 375-379. doi:org/10.1016/S0925-4005(97)80237-7

[80] V. Nanduri, A. K. Bhunia, S.-I. Tu, G. C. Paoli and J. D. Brewster, "SPR Biosensor for the Detection of L. Monocytogenes Using Phage-Displayed Antibody," Biosensors and Bioelectronics, Vol. 23, No. 2, September 2007, pp. 248-252. doi:org/10.1016/j.bios.2007.04.007

[81] "News and Market Update," Biosensors and Bioelectronics, Vol. 13, No. 3-4, March 1998, pp. i-ii. doi:org/10.1016/S0956-5663(98)90033-1

[82] A. Saito, T. Konno, H. Ikake, K. Kurita and K. Ishihara, "Control of Cell Function on a Phospholipid Polymer Having Phenylboronic Acid Moiety," Biomedical Materials, Vol. 5, No. 5, October 2010, pp. 054101-054107.

[83] Y. Tang, R. Mernaugh and X. Zeng, "Nonregeneration 
Protocol for Surface Plasmon Resonance: Study of HighAffinity Interaction with High-Density Biosensors," Analytical Chemistry, Vol. 78, No. 6, January 2006, pp. 1841-1848. doi:org/10.1021/ac051868g

[84] R. Karlsson, P. S. Katsamba, H. Nordin, E. Pol and D. G. Myszka, "Analyzing a Kinetic Titration Series Using Affinity Biosensors," Analytical Biochemistry, vol. 349, no. 1, February 2006, pp. 136-147. doi:org/10.1016/j.ab.2005.09.034

[85] H. H. Trutnau, "New Multi-Step Kinetics Using Common Affinity Biosensors Saves Time and sample At Full Access to Kinetics and Concentration," Journal of Biotechnology, Vol. 124, No. 1, June 2006, pp. 191-195. doi:org/10.1016/j.jbiotec.2006.01.006

[86] T. Wink, J. de Beer, W. E. Hennink, A. Bult and W. P. van Bennekom, "Interaction between Plasmid DNA and Cationic Polymers Studied by Surface Plasmon Resonance Spectrometry," Analytical Chemistry, Vol. 71, No. 4, January 1999, pp. 801-805. doi:org/10.1021/ac980679d

[87] S. R. Raz, M. Bremer, M. Giesbers and W. Norde, "Development of a Biosensor Microarray Towards Food Screening, Using Imaging Surface Plasmon Resonance," Biosensors \& Bioelectronics, Vol. 24, No. 4, December 2008, pp. 552-557.

[88] C. Garcia-Aljaro, X. Munoz-Berbel, A. T. A. Jenkins, A. R. Blanch and F. X. Munoz, "Surface Plasmon Resonance Assay for Real-Time Monitoring of Somatic Coliphages in Wastewaters," Applied and Environmental Microbiology, Vol. 74, No. 13, July 2008, pp. 4054-4058.

[89] D. Cui, X. Li, H. Cai, Y. Li, Z. Zheng and X. Chen, "Development of Surface Plasmon Resonance (SPR) Biochemical Analysis Instrument," Modern Scientific Instruments, Vol. 6, July 2001, pp. 34-38.

[90] M. Huang, Y. Shao, X. Sun, H. Chen, B. Liu and S. Dong, "Alternate Assemblies of Platinum Nanoparticles and Metalloporphyrins as Tunable Electrocatalysts for Dioxygen Reduction," Langmuir, Vol. 21, No. 1, December 2004, pp. 323-329.

[91] Y. Iwasaki, T. Horiuchi and O. Niwa, "Detection of Electrochemical Enzymatic Reactions by Surface Plasmon Resonance Measurement," Analytical Chemistry, Vol. 73, No. 7, March 2001, pp. 1595-1598.

[92] H. Sota, Y. Hasegawa and M. Iwakura, "Detection of Conformational Changes in an Immobilized Protein Using Surface Plasmon Resonance," Analytical Chemistry, Vol. 70, No. 10, April 1998, pp. 2019-2024.

[93] J. E. Gestwicki, H. V. Hsieh and J. B. Pitner, "Using Receptor Conformational Change To Detect Low Molecular Weight Analytes by Surface Plasmon Resonance," Analytical Chemistry, Vol. 73, No. 23, November 2001, pp. 5732-5737.

[94] Y. Liu, P. Liao, Q. Cheng and R. J. Hooley, "Protein and Small Molecule Recognition Properties of Deep Cavitands in a Supported Lipid Membrane Determined by Calcination-Enhanced SPR Spectroscopy," Journal of the American Chemical Society, Vol. 132, No. 30, July 2010, pp. 10383-10390.
[95] T. Kawaguchi, D. R. Shankaran, S. J. Kim, K. V. Gobi, K. Matsumoto, K. Toko and N. Miura, "Fabrication of a Novel Immunosensor Using Functionalized Self-Assembled Monolayer for Trace Level Detection of TNT by Surface Plasmon Resonance," Talanta, Vol. 72, No. 2, April 2007, pp. 554-560.

[96] J. Matsui, K. Akamatsu, N. Hara, D. Miyoshi, H. Nawafune, K. Tamaki and N. Sugimoto, "SPR Sensor Chip for Detection of Small Molecules Using Molecularly Imprinted Polymer with Embedded Gold Nanoparticles," Analytical Chemistry, Vol. 77, No. 13, May 2005, pp. 4282-4285.

[97] A. G. Frutos, S. C. Weibel and R. M. Corn, "Near-Infrared Surface Plasmon Resonance Measurements of Ultrathin Films. 2. Fourier Transform SPR Spectroscopy," Analytical Chemistry, Vol. 71, No. 18, August 1999, pp. 3935-3940.

[98] G. Arena, A. Contino, R. D'Agata, C. Sgarlata and G. Spoto, "Ordered Anchored Cavities at Work: A New and Rapid SPR-Based Method for the Detection of Trace Amounts of $\mathrm{Cs}^{+}$," New Journal of Chemistry, Vol. 29, No. 11, September 2005, pp. 1393-1395.

[99] C. Zhao, Y. J. Song, J. S. Ren and X. G. Qu, "A DNA Nanomachine Induced by Single-Walled Carbon Nanotubes on Gold Surface," Biomaterials, Vol. 30, No. 9, March 2009, pp. 1739-1745.

[100] S. Boujday, C. Methivier, B. Beccard and C. M. Pradier, "Innovative Surface Characterization Techniques Applied to Immunosensor Elaboration and TEST: COMPARING the Efficiency of Fourier Transform-Surface Plasmon Resonance, Quartz Crystal Microbalance with Dissipation Measurements, and Polarization Modulation-Reflection Absorption Infrared Spectroscopy," Analytical Biochemistry, Vol. 387, No. 2, April 2009, pp. 194-201.

[101] R. F. Dutra, R. K. Mendes, V. Lins da Silva and L. T. Kubota, "Surface Plasmon Resonance Immunosensor for Human Cardiac Troponin T Based on Self-Assembled Monolayer," Journal of Pharmaceutical and Biomedical Analysis, Vol. 43, No. 5, April 2007, pp. 1744-1750.

[102] W. Hu, C. M. Li, X. Cui, H. Dong and Q. Zhou, "In Situ Studies of Protein Adsorptions on Poly (pyrrole-co-pyrrole propylic acid) Film by Electrochemical Surface Plasmon Resonance," Langmuir, Vol. 23, No. 5, January 2007, pp. 2761-2767.

[103] A. Baba, R. C. Advincula and W. Knoll, "In Situ Investigations on the Electrochemical Polymerization and Properties of Polyaniline Thin Films by Surface Plasmon Optical Techniques," The Journal of Physical Chemistry B, Vol. 106, No. 7, January 2002, pp. 1581-1587.

[104] W. Hu, Z. Lu, Y. Liu and C. M. Li, "In Situ Surface Plasmon Resonance Investigation of the Assembly Process of Multiwalled Carbon Nanotubes on an Alkanethiol Self-Assembled Monolayer for Efficient Protein Immobilization and Detection," Langmuir, Vol. 26, No. 11, March 2010, pp. 8386-8391.

[105] C. C. Jung, S. B. Saban, S. S. Yee and R. B. Darling, "Chemical electrode surface Plasmon Resonance Sensor," Sensors and Actuators B: Chemical, Vol. 32, No. 2, 
May 1996, pp. 143-147.

[106] S. Wang, E. S. Forzani and N. Tao, "Detection of Heavy Metal Ions in Water by High-Resolution Surface Plasmon Resonance Spectroscopy Combined with Anodic Stripping Voltammetry," Analytical Chemistry, Vol. 79, No. 12, May 2007, pp. 4427-4432.

[107] Y. Iwasaki, T. Horiuchi, M. Morita and O. Niwa, "Analysis of Electrochemical Processes Using Surface Plasmon Resonance," Sensors and Actuators B: Chemical, Vol. 50, No. 2, July 1998, pp. 145-148.

[108] D. D. Schlereth, "Characterization of Protein Monolayers by Surface Plasmon Resonance Combined with Cyclic Voltammetry 'in Situ',' Journal of Electroanalytical Chemistry, Vol. 464, No. 2, March 1999, pp. 198-207.

[109] Y. Iwasaki, T. Horiuchi, M. Morita and O. Niwa, "Electrochemical Reaction of $\mathrm{Fe}(\mathrm{CN})^{3-/ 4-}{ }_{6}$ on Gold Electrodes Analyzed by Surface Plasmon Resonance," Surface Science, Vol. 427-428, No. June 1999, pp. 195-198.

[110] M. Manesse, V. Stambouli, R. Boukherroub and S. Szunerits, "Electrochemical Impedance Spectroscopy and Surface Plasmon Resonance Studies of DNA Hybridization on Gold/SiO Interfaces," Analyst, Vol. 133, No. 8, July 2008, pp. 1097-1103.

[111] D. Kambhampati, P. E. Nielsen and W. Knoll, "Investigating the Kinetics of DNA-DNA and PNA-DNA Interactions Using Surface Plasmon Resonance-Enhanced Fluorescence Spectroscopy," Biosensors and Bioelectronics, Vol. 16, No. 9-12, December 2001, pp. 1109-1118.

[112]F. Yu, D. Yao and W. Knoll, "Surface Plasmon FieldEnhanced Fluorescence Spectroscopy Studies of the Interaction between an Antibody and Its Surface-Coupled Antigen," Analytical Chemistry, vol. 75, no. 11, May 2003, pp. 2610-2617.

[113] J. Zhu, "Enhanced Fluorescence from $\mathrm{Dy}^{3+}$ Owing to Surface Plasmon Resonance of Au Colloid Nanoparticles," Materials Letters, Vol. 59, No. 11, May 2005, pp. 1413-1416.

[114] B. P. Nelson, A. G. Frutos, J. M. Brockman and R. M. Corn, "Near-Infrared Surface Plasmon Resonance Measurements of Ultrathin Films. 1. Angle Shift and SPR Imaging Experiments," Analytical Chemistry, Vol. 71, No. 18, August 1999, pp. 3928-3934.

[115] S. Patskovsky, A. V. Kabashin, M. Meunier and J. H. T. Luong, "Near-Infrared Surface Plasmon Resonance Sensing on a Silicon Platform," Sensors and Actuators B: Chemical, Vol. 97, No. 2-3, February 2004, pp. 409-414.

[116] A. V. Kabashin, P. I. Nikitin, "Interferometer Based on a Surface-Plasmon Resonance for Sensor Applications," Quantum Electronics, Vol. 27, No. 7, April 1997, pp. 653-654.

[117] X. Q. Chen, Q. A. Lv, "Phase-Shift Interferometry Combined with Surface Plasmon Resonance Effect for Two-Di- Mensional Bio-Surface Analysis," Optik-International Journal for Light and Electron Optics, Vol. 121, No. 9, May 2010, pp. 818-820.

[118] T. Hayano, Y. Yamauchi, K. Asano, T. Tsujimura, S.
Hashimoto, T. Isobe and N. Takahashi, "Automated SPRLC-MS/MS System for Protein Interaction Analysis," Journal of Proteome Research, Vol. 7, No. 9, September 2008, pp. 4183-4190.

[119] E. C. A. Stigter, G. J. de Jong and W. P. van Bennekom, "Development of an On-Line SPR-Digestion-NanoLCMS/ MS System for the Quantification and Identification of Interferon-Gamma in Plasma," Biosensors \& Bioelectronics, Vol. 24, No. 7, March 2009, pp. 2184-2190.

[120] P.-Å. Ohlsson, T. Tjärnhage, E. Herbai, S. Löfås and G. Puu, "Liposome and Proteoliposome Fusion onto solid Substrates, Studied Using Atomic Force Microscopy, Quartz Crystal Microbalance and Surface Plasmon Resonance. Biological Activities of Incorporated Components," Bioelectrochemistry and Bioenergetics, Vol. 38, No. 1, August 1995, pp. 137-148.

[121] A. Bund, A. Baba, S. Berg, D. Johannsmann, J. Lübben, Z. Wang and W. Knoll, "Combining Surface Plasmon Resonance and Quartz Crystal Microbalance for the in Situ Investigation of the Electropolymerization and Doping/Dedoping of Poly(pyrrole)," The Journal of Physical Chemistry B, Vol. 107, No. 28, June 2003, pp. 6743-6747.

[122] R. Schweiss, J. F. Lübben, D. Johannsmann and W. Knoll, "Electropolymerization of Ethylene Dioxythiophene (EDOT) in Micellar Aqueous Solutions Studied by Electro-Chemical Quartz Crystal Microbalance and Surface Plasmon Resonance," Electrochimica Acta, Vol. 50, No. 14, May 2005, pp. 2849-2856.

[123] D. G. Hanken, R. M. Corn, "Electric Fields and Interference Effects inside Noncentrosymmetric Multilayer Films at Electrode Surfaces from Electrochemically Modulated Surface Plasmon Resonance Experiments," Analytical Chemistry, Vol. 69, No. 18, September 1997, pp. 36653673.

[124] R. Georgiadis, K. A. Peterlinz, J. R. Rahn, A. W. Peterson and J. H. Grassi, "Surface Plasmon Resonance Spectroscopy as a Probe of In-Plane Polymerization in Monolayer Organic Conducting Films," Langmuir, Vol. 16, No. 17, July 2000, pp. 6759-6762.

[125] V. Chegel, O. Raitman, E. Katz, R. Gabai and I. Willner, "Photonic Transduction of Electrochemically-Triggered Redox-Functions of Polyaniline Films Using Surface Plasmon Resonance Spectroscopy," Chemical Communications, No. 10, April 2001, pp. 883-884.

[126] A. Baba, J. Lübben, K. Tamada and W. Knoll, “Optical Properties of Ultrathin Poly(3,4-ethylenedioxythiophene) Films at Several Doping Levels Studied by In Situ Electrochemical Surface Plasmon Resonance Spectroscopy," Langmuir, Vol. 19, No. 21, September 2003, pp. 90589064.

[127] M. Riskin, B. Basnar, V. I. Chegel, E. Katz, I. Willner, F. Shi and X. Zhang, "Switchable Surface Properties through the Electrochemical or Biocatalytic Generation of $\mathrm{Ag}^{0}$ Nanoclusters on Monolayer-Functionalized Electrodes," Journal of the American Chemical Society, Vol. 128, No. 4, January 2006, pp. 1253-1260.

[128] A. K. Sheridan, P. Ngamukot, P. N. Bartlett and J. S. 
Wilkinson, "Waveguide Surface Plasmon Resonance Sensing: Electrochemical Desorption of Alkane Thiol Monolayers," Sensors and Actuators B: Chemical, Vol. 117, No. 1, September 2006, pp. 253-260.

[129] F. Mirkhalaf, D. J. Schiffrin, "Metal-Ion Sensing by Surface Plasmon Resonance on Film Electrodes," Journal of Electroanalytical Chemistry, Vol. 484, No. 2, April 2000, pp. 182-188.

[130] Rajan, S. Chand and B. D. Gupta, "Fabrication and Characterization of a Surface Plasmon Resonance Based Fiber-Optic Sensor for Bittering Component-Naringin," Sensors and Actuators B: Chemical, Vol. 115, No. 1, May 2006, pp. 344-348.

[131] M. Péter, M. A. Hempenius, E. S. Kooij, T. A. Jenkins, S. J. Roser, W. Knoll and G. J. Vancso, "Electrochemically
Induced Morphology and Volume Changes in SurfaceGrafted Poly(ferrocenyldimethylsilane) Monolayers," Langmuir, Vol. 20, No. 3, January 2004, pp. 891-897.

[132] X. Yao, J. Wang, F. Zhou, J. Wang and N. Tao, "Quantification of Redox-Induced Thickness Changes of 11Ferrocenylundecanethiol Self-Assembled Monolayers by Electrochemical Surface Plasmon Resonance," The Journal of Physical Chemistry B, Vol. 108, No. 22, April 2004, pp. 7206-7212.

[133] F. S. Damos, R. C. S. Luz and L. T. Kubota, "Determination of Thickness, Dielectric Constant of Thiol Films, and Kinetics of Adsorption Using Surface Plasmon Resonance," Langmuir, Vol. 21, No. 2, January 2005, pp. 602-609. 